\title{
Systemic risk elicitation: Using causal maps to engage stakeholders and build a comprehensive view of risks
}

\section{by}

Fran Ackermann (corresponding author)

Curtin Business School, Curtin University, GPO Box U1987 Perth, Western Australia 6845; fran.ackermann@curtin.edu.au.+61892661835

Susan Howick

Management Science Department, Strathclyde Business School, 40 George Street, Glasgow, Scotland G1 1QE; susan.howick@strath.ac.uk

\section{John Quigley}

Management Science Department, Strathclyde Business School, 40 George Street, Glasgow, Scotland G1 1QE; john.quigley@strath.ac.uk

$$
\text { Lesley Walls }
$$

Management Science Department, Strathclyde Business School, 40 George Street, Glasgow, Scotland G1 1QE;

$$
\text { Lesley.walls@strath.ac.uk }
$$

Tom Houghton

Management Science Department, Strathclyde Business School, 40 George Street, Glasgow, Scotland G1 1QE; tom.houghton@strath.ac.uk 


\title{
Systemic risk elicitation: Using causal maps to engage stakeholders and build a comprehensive view of risks
}

\begin{abstract}
As evidenced through both a historical and contemporary number of reported over-runs, managing projects can be a risky business. Managers are faced with the need to effectively work with a multitude of parties and deal with a wealth of interlocking uncertainties. This paper describes a modelling process developed to assist managers facing such situations. The process helps managers to develop a comprehensive appreciation of risks and gain an understanding of the impact of the interactions between these risks through explicitly engaging a wide stakeholder base using a group support system and causal mapping process. Using a real case the paper describes the modelling process and outcomes along with its implications, before reflecting on the insights, limitations and future research.
\end{abstract}

Keywords: Problem structuring, risk analysis, group decision making

\section{INTRODUCTION}

In both the public and private arenas large complex projects are frequently beset with significant problems causing them to both run over time and budget (Flyvberg et al, 2003). Whilst there are a number of tools and techniques developed to manage projects, for example Project Risk Registers or Critical Path Analysis (Project Management Institute 2011) these, as yet, do not appear to have eradicated cost overruns as expensive events (risks) continue to occur. Moreover, while good risk management can help, there appears from both the literature and practice to be a predisposition to focus on technical and financial risks rather than take a wider, more comprehensive view (Ackermann et al, 2007) thus limiting the effectiveness of the activity.

In addition to taking a narrow view, another contributor to the complexity of managing risks is the involvement of an increasingly extensive array of stakeholders. Not only is this due to large turn-key projects typically involving a wide range of suppliers and sub-suppliers, but also the inclusion of consultants, joint venture partners, local/national governmental authorities and the general public (Williams, 2002). Each of these stakeholder bodies has different power and interest bases (Ackermann and Eden, 2011a) and has its own understanding of the objectives of the project and how they tie in with their own core organizational goals (Ackermann and Eden, 2011b). In addition, each of these stakeholders not only has different working cultures and languages (Engwall, 2003) but also different financial imperatives making effective collaborative working difficult. Analysis on projects that have experienced considerable overruns have found the risks relating to politics (Engwall, 2003) suppliers, customers, contractors, force majeure events, etc. often cause the problems 
(Ackermann et al, 2007) - corroborating the point regarding the multiplicity of stakeholders and their attendant problems.

Furthermore, many of the techniques take a very discrete view in terms of analysing and managing risk. For example, project risk registers work on the underlying assumption that risks exist independently from one another (Morris and Pinto, 2004). However, this assumption does not work in practice with an increasing body of researchers arguing that risks have significant implications for one another rendering management more difficult (Williams, 2000). For example, Williams et al (1997) argue that 'the impacts that some risks have might compound the impact of others - so the effect of two risks might be more than the sum of the two individual effects thus reflecting systemicity' (p.345). This view is clearly presented in work by Eden et al. (2005) who describe the non-linear growth as 'amoebic'. However, it should also be noted that although other recent articles (Fang et al, 2003; Kazemi and Mosleh, 2012) aspire to modelling dependencies between risks in large complex projects they still tend to anchor on the classical risk identification methods, despite acknowledging their limitations. Finally Hartman (2003, p21) underlines the prevailing view that projects are becoming increasingly byzantine commenting that 'risk management is not only more complex, but more important than ever' recognising the emergence of a preference for turn-key projects.

Although as noted above, there are a number of tools used for project risk management including Monte Carlo simulation, decision trees, risk breakdown structures, probability and impact matrices, Project Risk Registers (PRR) are "the most common administrative device" (Williams 1993 p7) for identifying, assessing, attributing ownership of and management of risks. The importance of the PRR is also emphasised by the PMBOK (PMI 2004) which identifies that PRR has a role in 8 out of the 9 steps involved in the project risk management process. However, as noted above there are a number of limitations with this tool. It is therefore important to recognise that new approaches for managing risk in projects taking account of multiple perspectives in terms of the wide consideration of risks and their management, a broad comprehensive surfacing of risks, and an appreciation of systemicity, are necessary, particularly in today's world of tightening economic conditions, increasing volatility and progressively more complex projects. In reviewing these considerations, problem structuring methods (Rosenhead \& Mingers, 2001) and support systems for group decision making - Group Support Systems (Jessup and Valacich, 1993) seem well placed. For example, problem structuring methods, such as causal mapping, provide a way of capturing the systemic view of an issue (Ackermann and Eden 2011b). In addition, group support systems provide a way in which multiple perspectives and thus a wide range 
of risks can be gained from a range of stakeholders in a fair and structured manner. This supports the development of a comprehensive view of a situation.

This paper therefore describes the use of a process that engages a problem structuring method, causal mapping, within a group support system to elicit a comprehensive view, from a wide range of stakeholders, of the risks facing a project. The process aims to alleviate, at least to some extent, the considerations discussed above and is one that has been applied extensively in practice to support a management team in their complex and often strategic decision making processes. By incorporating knowledge from the field of problem structuring, the process provides a means of going beyond the traditional approaches to risk analysis to one that is inclusive, comprehensive and systemic. The paper thus commences with a brief introduction to a case study where the process has been used, before examining the basis for the process, and finishing with conclusions, limitations and next steps/future work.

\section{CASE STUDY}

The power station providing most of the energy for the Shetland Islands, a small group of islands at the northern end of Scotland, required replacement (due partly to age and partly to the changes in emissions regulations). The design of the new power station would be informed by an analysis of Shetland's energy requirements and the availability and feasibility of other generation options to meet this demand. Moreover, as part of Scotland's and the UK's wish to increase renewables (to help manage climate change), as well as recognising the impact of rising fuel prices (experienced particularly in Shetland due to its remote location), there was a desire to use renewables to meet a greater proportion of energy demand and reduce reliance on fossil fuels. However, incorporation of new renewables is constrained by the capacity of the existing electricity grid and a lack of a grid connection to the mainland. Thus, Scottish Hydro Electric Power Distribution (SHEPD) designed the Northern Isles New Energy Solutions (NINES) project to trial a range of smart grid innovations to reduce capacity constraints and increase exploitation of renewable energy resources, while maintaining energy security - 'keeping the lights on'. The NINES project outcomes would therefore inform the design of the new power station particularly its capacity.

The NINES project thus assesses the potential of different generation portfolios combined with smart grid technologies to meet current and future demand. This requires understanding the area's energy demands ranging from domestic use to public services, e.g. hospitals, factories and refineries. In addition, it is important to understand the network implications of the generation options which differ in terms of voltage and frequency 
variance, reliability of supply and transmission formats. Finally, there is an imperative to build longevity into the solution - as the option chosen will have to operate for at least 20 years and therefore needs to be robust against a range of different uncertain and shifting futures.

SHEPD invited academics with competences in electrical/power engineering, economics and management science (focusing on risk) to be involved in the NINES project. The authors of this paper were involved in the risk identification and quantification element of the project. The particular objective was to identify, structure, quantify and work through the implications of risks pertaining to the NINES project with regards to the different design options as well as taking note of the wider environment as seen by key stakeholders. Inputs to the framework would be existing data/documentation, and extensive stakeholder discussions elicited through workshops and semi-structured interviews.

The project kicked off with a series of three risk workshops. The first workshop involved the NINES team (University researchers and energy company project managers), the second involved Shetland islanders (including councillors, wind farm owners, etc.) and the last involved technical members from the energy company (SHEPD). Each workshop involved between 8 and 16 people ensuring a wide range of perspectives were incorporated as well as gaining buy in and ownership. The selection of participants was agreed between the NINES project manager and the workshop facilitators. The facilitators sought to bring together a range of experts from within the project (offering suggested job titles/roles for participants) in addition to a range of external stakeholders that had significant interest in the NINES and repowering projects to ensure broadest coverage and ownership. However, the final selection was influenced by the project managers' personal view of those people who would provide useful input to the sessions and those for whom it was strategically important to include. Availability on scheduled workshop days also influenced the final list of participants.

\section{THE PROCESS}

As the above discussion regarding project risk illustrates there are considerable difficulties in managing projects given their growing complexity. It could be argued therefore that managing project risk, particularly state-ofthe-art projects, is akin to resolving wicked or complex problems (Ackoff, 1981; Rittel and Weber, 1973) and thus using methods such as problem structuring/ Soft OR (Rosenhead and Mingers, 2001) may provide valuable means of managing complexity. Both forms of modelling - project risk management and resolution of wicked problems - attend to eliciting multiple perspectives accrued from different stakeholder bodies yielding a more comprehensive appreciation, support the capturing and exploring not only the risks/issues but how they impact 
one another addressing systemicity, and contend that it is critical to develop a shared understanding of the whole in order to determine appropriate ways forward. Thus, incorporating elements from the Soft OR/problem structuring methods arena into risk analysis and management appears logical and coherent.

Moreover as noted in both modelling areas, finding a manageable process that is not unwieldy demanding large amounts of time and/or resources is paramount. This requirement entails finding a means of managing the complexity, and so not losing the systemic benefits, whilst also attending to the demands of organisational life (for example, managing competing priorities for time, organizational culture/politics etc.). As such the process design for the risk workshops was based on an existing body of work which focused on the use of causal mapping to capture not only the risks but also their impacts upon one another as well as the use of a Group Support Systems - GSS (Jessup and Valacich 1993). Causal mapping is a technique based on personal construct theory (Kelly 1957) and developed to be used either individually or in groups. The maps themselves are representations of perceptions of a situation which can be woven together with the views of others if a group elicitation mode is adopted. From this integration of views directed graphs comprising nodes and relationships are compiled. There are clearly defined formalisms for the capture of nodes and relationships with the networks enabling both exploration and analysis of the resultant structure. For a fuller description of causal mapping see Bryson et al (2004).

Group decision support methods enable greater productivity through their ability to support participants in contributing simultaneously to the unfolding representation - by providing participants with the facility to enter contributions into a shared space. In addition, these systems also support anonymity and thus reduce the conformity pressures that participants experience when being identified with specific contributions (Jessup and Tansik, 1991; Valacich et al, 1992).This is particularly useful for avoiding negative group behaviours such as Group Think (Janis 1972), Abilene Paradox (Harvey 1988) etc.

One reason behind this choice was that there had already been a precedent for GSS supported causal modelling (Ackermann and Eden, 2005; Howick et al, 2006) illustrating that the GSS could help with managing the multifarious demands on management time through enabling the rapid gathering of views, causal relationships and preferences and enabling considerable progress to be achieved in a relatively short duration. Moreover the particular GSS software to be used - Group Explorer - enabled the structuring of contributions, management of complexity, and an enhanced understanding of the systemic situation through building a causal map amenable to analysis (Ackermann 2012), helping to manage the complexity and provide participants with the means of 
navigating the emergent structure. In addition, Group Explorer enabled participants to negotiate effective management options (Ackermann and Eden, 2010; Eden and Ackermann 2010).

The workshops followed mostly the same design, namely the generation of risks, consideration of the relationships between risks (risk systemicity) and the identification of priorities. Group Explorer (GE) ensured that models of around 200 contributions could be built in a relatively short period of time with each workshop taking between 4 and 5 hours. Participants were provided with consoles through which they could enter risk statements, links between the risks, and priorities. In addition, a public screen provided the facility to display the collation of all of the views and facilitated continual amendment and development of the emerging picture. In addition, the facilitator had access to a third computer which displayed participant activity allowing her to see which participants were actively contributing, what was being contributed, and whether there was universal agreement on priorities.

Thus the key stages in the process were as follows:

3.1 The elicitation of risks as perceived by the workshop participants

An objective of the elicitation process was for participants to consider a wide range of risks, going beyond technical risks to consider political, environmental, strategic risks etc. This was a key consideration for the client organisation for a number of reasons. Firstly the project was a significant departure from the usual projects embarked upon and thus a more comprehensive view was considered necessary. It would help in determining which risks needed immediate attention, which need to be monitored and would help alert those working on the project as to possible problems. Secondly, as the project was being monitored by the regulator, considering concerns from the wider stakeholder body was both politically important but also beneficial in achieving the first objective. Inclusion of stakeholders from all parts of the project, each with their own specific concerns, helped to achieve this objective. Selection of these stakeholders was informed by considering the depth and breadth of knowledge held by participants, their power and interest bases and more pragmatically, their availability. Whilst those having a risk management responsibility were involved, a more inclusive selection was chosen reflecting the novel nature of the project and the political ramifications.

For the workshop a definition of risk was adopted that was sufficiently broad to encourage as comprehensive range of risks to be surfaced. This definition was 'an uncertain event or condition that, if it occurs, has a positive or negative effect on the projects objectives' PMBOK (2013 p310) as this was familiar to many. 
Participants were paired, allocated a laptop computer, asked to consider risks that may be associated with the NINES project and type these into GE. Each risk not only appeared on the participant's console but also on the public screen allowing participants to 'piggy back' off each other and trigger as comprehensive a range of risks as possible (see figure 1). The process enabled fast elicitation of risks as multiple participants could contribute at the same time. To support this activity the facilitator attempted to cluster the risks into themes based on their content - allowing participants to cognitively manage the growing body of material rather than face overload. The clusters also enabled a quick overview of the themes to be conducted allowing participants to see what had been generated and prompting further contributions as missing areas became obvious. As a result of the clustering, being involved in the gradual build-up of the unfolding material and also use of an extremely high resolution projector, participants were able to read, absorb and work with the material displayed on the screen. In addition, regular print outs of the maps were provided to the group to allow for more detailed scrutiny.

Figure 1 about here - photo of group working

\subsection{Structuring and linking of the risks}

Once the rate of participants' contributions had significantly slowed down and it was perceived that they had exhausted their reservoir of risks, the process moved on to explore how the risks impacted one another. This part of the process facilitates consideration of the systemicity of the risks (Howick et al, 2006; Ackermann et al, 2007; Williams et al 1997) highlighting that risks do not occur in isolation from one another and reflecting the connective nature of the PMBOK definition. As already noted, it is often the interaction between different types of risk that can cause the most damage to a project (Eden et al, 2005; Eden et al 2000; Williams et al 1995). A risk event in one area/category may cause, or contribute to the likelihood of a risk event somewhere else. For example, a supplier going out of business may have an impact on a particular aspect of the engineering arena or a change in government may affect funding allocations. Thus, risks can be seen as a network of interrelated possible events, which may be referred to as 'risk systemicity'. Risks are linked to one another through the use of arrows where an arrow from 'Risk A causes, exacerbates or promotes Risk B' (Williams et al 2004, p221). As risks are linked to one another, a 'risk map' is created (an example of this can be seen in Figure 2 below). This modelling process not only enabled the group to move from a fairly divergent set of views to a more convergent set but also triggered the generation of new material as the rationale for the links was explicated and captured.

Figure 2 about here 


\subsection{Prioritisation of risks}

In each of the workshops, the facilitator identified those risks which were both substantially impacted by, and/or had an impact on, the other risks in the map using central and domain analyses ${ }^{1}$ (Eden and Ackermann, 1998). These risks were then focussed on during the next part of the workshop. Using GE, participants were asked to prioritise these 'key' risks with respect to likely probability and impact. At this stage, only relevant sections of the risk map were displayed to reduce cognitive overload so that participants could focus on those risks that were seen to be of most importance. Again, this activity was predominantly carried out in pairs ${ }^{2}$, enabling discussion amongst each pair of participants in addition to discussion between the different pairs when the final prioritisation was displayed on the public screen. This discussion not only enabled participants to explain their own reason for prioritisation, but also allowed them to consider other people's views, broadening their understanding of the perspectives of other stakeholders and developing a more holistic appreciation for the potential risks and their consequences. This prioritisation was undertaken by asking participants to rate the selected 'key' risk statements on a scale of 0 to 100.0 related to the risk which they believed would have the least impact on the project if it occurred whereas 100 related to the risk which they believed could have the greatest impact on the project if it occurred. Other risks were then positioned relative to these two anchor points.

A second prioritisation activity was also carried out. Participants were asked to consider those risks which they believed were most probable to occur in the short term i.e. the next 6 months and those risks that they believed were most probable to occur in the long-term i.e. in 2 years when the final portfolio of energy sources was to be confirmed to the regulator. This stage of the process enabled identification of those risks that needed most attention and thus required careful management both immediately and in the near future. For some risks, there was general consensus within the results from the prioritisation activity. However, for other risks, time was allocated to explore the differences in participants' views. The result of this step was to provide SHEPD with a prioritised agenda for risk management to provide guidance on where to focus their limited resources.

3.4 Enhancing the risk map after the workshop

\footnotetext{
${ }^{1} \mathrm{~A}$ domain analysis calculates the number of links directly in and out of a statement (risk). The central analysis not only calculates the immediate links in and out but in addition incorporates statements (risks) linking into/out of the statements linking in and out but with a diminished weighting

${ }^{2}$ In one of the workshops due to the uneven number of participants, one participant worked solo; in another of the workshops, there was a trio of participants using a console
} 
Participants were given the opportunity to add to or amend the risk map after the workshop. Workbooks displaying themed views from the risk map were sent to participants to provide them with the opportunity to add further risks, or to add or amend links between the risks. One reason for this activity was the limited time available in the workshops and thus the appreciation that participants may wish to include further material after leaving the workshop. A second reason was to promote the risk map as a dynamic (rather than static) tool which can be updated as new knowledge becomes available.

\subsection{Feedback on the process}

Interviews with individual participants were carried out following two of the workshops ${ }^{3}$, partly as an additional way of gaining further material as a part of step (iv), but also to gain feedback on the process. This feedback was of particular importance in order to enhance the process for the second tranche of workshops to be carried out a year later.

\subsection{Analysis of the resultant material}

Once the workshop maps had been augmented with the material generated during the interviews, the three models were analysed to determine their constituent properties (Ackermann and Eden, 2011; Sterman 2000). Each model was considered separately as their idiographic properties provided important insights in relation to managing the messy complex situation. Moreover as the workshops were being conducted to inform the client SHEPD (rather than participants working to determine a single unified representation) there was no demand to integrate the models - the client preferred to keep the insights located with each workshop as the particular mix of participants provided valuable contextual information. However, it was possible to gain some form of triangulation as insights that emerged across all three workshops gained greater salience. Details of the analysis and the resulting insights are discussed below.

\subsection{Reporting findings}

The output from the workshops and the subsequent analysis was reported back to SHEPD. For each workshop, the report highlighted the themes that emerged, the most significant risks and those risks that were perceived by the participants to be of priority. In addition, overlapping themes between the 3 workshops were discussed.

\footnotetext{
${ }^{3}$ they were not used following the first workshop with the NINES team as this was seen as a pilot workshop and members were in regular contact with one another
} 
Appendix 1 provides an overview of the stages with associated benefits, limitations, process, outputs and additional contributions noted.

\section{INSIGHTS FROM THE ANALYSIS}

As mentioned in section 3.6, each of the risk maps created from the three workshops was analysed to determine their constituent properties. This involved examining the extent of the perceived systemicity of the risk maps, identifying the most significant risks, considering the potential impact of any feedback loops and a general comparison of the maps created from each of the workshops. Each of these activities will be considered below along with the insights gained. It should be noted the insights gained are a mixture of insights from both the perspective of the researchers (focussing on the process of the workshops and analyses) as well as the client (focussing on the content of the workshops and the resulting analyses).

- Systemicity of the risk map: An initial examination was made of the ratio of the number of statements in the maps to the number of links as this provides some insights into the perceived systemicity of the network. The three workshops revealed statement link ratios of 145:150, 207:290, and 156:197. A typical ratio when working with causal maps is around 1:1.3 or 1.4. The low ratio in the first workshop (NINES team) highlighted the paucity of links elicited. This relatively thinly linked structure was due to the focus for the workshop. It was seen as a pilot workshop where time had been concentrated on considering themes rather than links (for example themes relating to the environment etc.). Although the consideration of common themes was introduced in previous situations to great effect, this activity was found to be of less value to understanding the structure of the risk network. The focus on themes whilst creating the maps was therefore removed from the later workshops. Moreover, the thinly linked structure in the first workshop resulted in some areas of opaqueness in the risk map where risks were not clearly connected into the network and their meaning was not totally transparent. This occurrence was therefore reduced in the later workshops through spending more time considering the impact that a risk would have on the project. This highlighted that, processually, there was more of a need to understand the systemicity than the potential themes.

- A second point to note is that the number of links/statements correlated closely with the number of participants (there were more participants in the second workshop than the first and third). The second workshop (Shetland) also involved participants with a wider variety of backgrounds. It therefore also 
suggests that involving different perspectives generated more information than when only involving those apparently embedded with the project i.e. the NINES team.

- Identification of the most significant risks: Two analyses mentioned above, domain and central, which concentrate on identifying significant risk statements, were run as part of the process of identifying emergent themes that naturally fall out of the network (Bryson et al, 2004). From these analyses 6-8 themes were highlighted for each workshop, identifying groups of risks which should be considered together as a part of the risk management process as they are interrelated and thus may have an impact on one another. Rather than simply providing an extensive list of risks which focusses management on each individual risk, it enables clusters of risks to be focussed on together, ensuring that any action taken is appropriate for the whole cluster of risks. In addition, five common themes were highlighted across the three workshops indicating areas that were of concern across the wide range of participants and thus possibly were particularly important and required further attention. These included issues such as protecting reputation/brand, managing staffing and project overruns (the first two being away from the traditional financial/technical considerations).

Furthermore, when clustering the material into themes, information was gained from the shape of the map sections relating to a theme. For example, if the section of the risk map was a broad horizontal shape, then this meant that a breadth of knowledge in the area was demonstrated, but there appeared to be a lack of depth of knowledge. Similarly, a narrow vertical shape demonstrated depth rather than breadth of knowledge round the theme. This observation may suggest further work is required in attempting to better connect the themes with the rest of the risk network. Another explanation for the 'shapes' may be the particular mix of participants in the workshop and may suggest additional people being asked to contribute to the process. In any case, potential areas of weakness in knowledge are highlighted to the client thus moving towards a more encompassing risk process.

- $\quad$ The impact of feedback loops: This included determining whether there were any feedback loops suggesting dynamic behaviour (Sterman, 2000). Once in place, this type of behaviour can be difficult to resolve (Cooper, 1994; Williams, 1995) and thus its identification and consideration with respect to the project was seen to be an important part of the analysis of the risk map. An example of a feedback loop that was highlighted is shown in Figure 3. 
Figure 3: Extract from the SHEPD risk map that includes feedback loops

From the common theme of 'managing staff' the feedback loops in Figure 3 highlight the importance of ensuring adequate skill and knowledge in staff when operating the systems as this will ensure SHEPD perform well which may impact being awarded future projects which, in turn, will impact their reputation and thus the ability to attract future good staff.

- Comparison of risk maps: There were some interesting results when comparing the second and third workshops (Shetland and SHEPD). The material from the SHEPD workshop demonstrated more common/convergent thinking. Although this demonstrated clarity of direction which can be useful when implementing a project, it potentially lacked the creativity of 'thinking outside of the box'. The Shetland workshop brought a different, and wider, perspective to the consideration of risk, helping SHEPD to augment their thinking. This broadened SHEPD's perspective on potential issues well beyond what would normally be covered in a standard risk register. For example, only 12 risks were identified in the NINESspecific risk register provided by SHEPD and while probability and impact are used to rank these in importance, as was carried out in the workshop, no explicit connection or linkage is made between them ${ }^{4}$. Moreover the risks can be clustered into 3 broad categories; technical, commercial and project delays, suggesting a somewhat narrower focus than was apparent in the workshops. The Shetland workshop also added to SHEPD's understanding of the perception of the wider stakeholders involved in the project. Communication with the local community formed a crucial part of the project, thus understanding the concerns of the participants helped SHEPD to tailor communication with respect to the project more appropriately to gain buy-in from the local community. A second insight gained was that even though the three workshops were intended to be done at similar times, practicalities meant that there were a few weeks in-between each. The material gathered was different due to the different participants; however it was also noted that emphasis changed depending what was happening on the project at that point in time i.e. what was forefront of participants' minds. This highlighted the dynamic nature of the project and the need for a project risk process that captured this changing profile e.g. regular risk workshops. The regularity of such workshops would be project dependent based on the length of the project, and a recognition of how

\footnotetext{
${ }^{4}$ Note that the version the authors received was revision 6 and it is likely that risks previously identified but subsequently mitigated had been removed from the register
} 
dynamic the project environment is. However this needs to be tempered with the practicalities of getting potential participants together appreciating that recent work has explored the effectiveness of carrying out 'virtual' workshops where participants contribute at a distance from the facilitator from different locations (Duarte and Snyder, 1999; Maznevski and Chudoba, 2000; Pauleen and Yoong, 1987; Scotland et al, 2011). In addition, events may occur during the life of a project which have a significant impact on the perception of future risks and thus warrant an additional workshop to take place. For example, the approval of a large windfarm in Shetland has brought a new perspective to its future energy provision, but also a division in support in the local community.

In addition to the analysis discussed above, the results of the risk prioritisation activities were reported back to the client. This provided SHEPD with a prioritised agenda for risk management to provide guidance on where to focus their efforts as SHEPD, along with most organisations, had limited resources available to allocate to risk management. The systemic nature of the process allowed these resources to be focused on those risks which were perceived to be most worthy of attention to ensure the successful implementation of the project. In particular, the process highlighted areas of concern such as the impact of local community buy-in and ensuring there are sufficient available skilled workforce (see Figure 3) which were areas not traditionally covered by the company's more technically focussed risk assessment process.

\section{CONCLUSIONS, LIMITATIONS AND NEXT STEPS}

The introduction to this paper concluded that there was a need for new approaches for managing risk in projects to take account of multiple perspectives, a broad comprehensive surfacing of risks, and an appreciation of the systemic nature of risk. This paper has presented a process which enables each of these concerns to be attended to. Multiple perspectives have been taken into account by including a range of key stakeholders in the process in an efficient, rather than time consuming, approach. The process specifically focusses on surfacing a broad range of risks and revealing systemicity and systemic properties, such as embedded feedback links, between risks. This would not have been possible without taking a holistic view of both risks and their potential impacts. See appendix 1 for a summary of benefits, limitations and contributions of the process to risk management. It should be noted that the dynamic nature of risks has not been considered explicitly in this paper as this consideration will form an important element of the next stage of the project and is discussed later in this section. 
The risk workshop process presented above has been tested in 3 workshops and has proved valuable to the client organisation (as evidenced through feedback from participants below). However, it is appreciated that 3 is a small number and refinement of the process will be needed based on the experience to date. Nevertheless, the organisation has benefited in a number of ways:

- The workshops are an interactive process and thus focus the attention of the participants. They stimulate active participation (for example in the Shetland workshop, 63 risk statements were generated in 11 minutes), promoting understanding of the numerous risks and their ramifications, and help build up a comprehensive view of the NINES project

- The workshop process offers a different way in which to consider risk assessment and management. The maps represent scenarios that demonstrate the systemicity of risk, rather than considering risks in isolation from one another and thus potentially missing impacts that may occur due to the interaction between risks.

- The process is inclusive by bringing together the perspectives of multiple stakeholders in the project (from project team members to local councillors and wind farm developers). This also encourages cross disciplinary learning through an appreciation of how risks from each part of the project impact one another. This provides participants with a holistic view of the risks in the project.

A key value added to the organisation has been an improvement on traditional methods through the extension of its risk assessment process beyond the organization's standard business risk register (see the quote from the NINES project manager below). As previously highlighted, project risk registers assume that individual risks are independent from one another (Morris and Pinto, 1987). In addition, in many businesses, the risk register does not take such a comprehensive view of risk and does not involve as many perspectives. It is also rarely a dynamic process, enabling risk systemicity and its evolving nature to be tracked over the life of a project.

Initial feedback, gathered from participants, confirmed many of the benefits discussed above. This suggested that participants valued each aspect of the process discussed above, as seen through the following quotes:

- Comprehensive: "Covered lots of potential risks that we hadn't thought about before.”

- Interaction between risks: "Given the diversity of group, I was impressed how some of the risks tied into each other in both the same and other areas. The cross-links were interesting. I was interested in links that come into my area." 
- Inclusive: "I was very impressed - it got the views of a lot of people and was structured"

- Holistic: "Got the big picture... rather than looking only at your own area of responsibility."

- Improvement on traditional methods: "The traditional method almost tries to get to answers first, as risks are based on experience and previous knowledge... However the workshop approach takes a different view by focussing on links and thus picked up on a number of things behind (traditional) risks that wouldn't have been thought about. We wouldn't have seen these links in the traditional method as you 'go where you know'. Also it is like-minded/similar people that prepare the risk assessment each time. However with workshop a wider group of people involved and thus takes you in a different direction." This final quote was of particular interest as it came from the NINES project manager who had overall responsibility to manage risks on this project.

As noted from the above quotes, the inclusion of problem structuring (through the causal mapping) supported the interactive and comprehensive capturing of risks and the group support system enabled participants to believe they had improved understanding of risks beyond their established risk analysis methods.

The above recognises that the described process brought together a number of perspectives on the project. In addition to supporting the risk management process, there were also additional benefits for the management of the project. For example, it was imperative that SHEPD involved the Shetland community during the project. Ensuring that the community were bought into the project and the different activities which were a part of the project was seen to be crucial to its success. However, the project manager stated that the workshops played a key role in involving the community and understanding their perspectives on the project. A key challenge when working with multiple stakeholders on a project can be difficulties in communication amongst the different parties (Ackermann and Eden 2010). The types of workshops described in this paper can help in bringing the parties together and supporting discussion on aspects of the project. Indeed similar types of workshops could be used to support other aspects of project management or even project design where communication is key.

\subsection{Limitations and Future Research}


Although a number of benefits have been identified from the workshop process, it is recognised that there are some limitations. Each of these limitations will need careful consideration and undertaking further workshops will help to improve the process.

Identified limitations are as follows:

- The workshops are good at providing buy-in and ownership for those that participate in them.

However, if the output from the process is required to be reported to other parts of an organisation, then people may find it difficult to gain a full appreciation of the contents of the maps - they can be overwhelming. People have reported that they prefer multiple risks reported as lists. This is not surprising due to most peoples' lack of familiarity with maps and a systems thinking approach, and thus feeling more comfortable in reducing problems into discrete, manageable issues (Ackermann 2012). Thus when reporting the outcome of the NINES workshops a mixture of maps and lists were used with the lists comprising the key themes that surfaced from the workshops (along with indented further detail), enabling some level of the systemicity of the risk structure being retained in the reporting process. This issue of determining an accessible representation of the complexity of the risk network is an area that will benefit from further work.

- The ideal situation would be to include all key stakeholders in the workshop process as the final mix of participants significantly impacts the overall outcomes of the workshops. A key stakeholder will have knowledge that is germane to the project or power to influence project completion. However, the selection process involved taking account of clients' wishes with recognising that there were a limited number of places available alongside recognising stakeholders' availability means that there are always going to be some key stakeholders missing. For example, in the NINES project it was not possible to include the regulator and a key supplier in the process. In addition, some members of the group that were to be a part of the process were not able to make the arranged dates due to diary restrictions. The process needs to consider how their perspectives can be taken into account to ensure as comprehensive coverage of issues as possible and how they can gain buy-in to the outcomes of the process, particularly in light of the point made above.

- When gaining feedback from participants, one person noted that they felt that more time could have been spent eliciting risks. Workshop participants are often very busy people, who can only give the process a restricted amount of time. The 4-5 hours for the NINES workshops meant that the balance of 
time between eliciting, linking and prioritising risks had to be carefully planned. It is crucial that the workshops are kept to a manageable timeframe otherwise they will simply not work in practice; therefore it was not believed to be practical to extend them. More time spent on eliciting risks may provide a richer and wider set of risks, but this leaves less time for linking the risks and thus not fully capturing the extent of the systemicity in the risks. Within each of the workshops, a judgement was made by the facilitator to move onto linking risks when it was perceived that the participants' rate of risk generation had significantly reduced (in essence using a Pareto type judgement call). This was informed through the software being able to reveal the rate of risk generation taking place and thus, when most participants had' fallen silent', the decision to move to the next step could be considered. The balance of time between each activity is crucial and it is anticipated that this will be fine-tuned as further workshops are undertaken.

- Participants were sent workbooks after the workshops so that they did not feel that the time spent eliciting or linking risks was too restricted. However, not all participants returned material from this activity. When in a workshop, participants dedicate their time to the task in hand, however outside this event the task may not have been given their full attention, with other work taking priority. One reason for this may be that as the workbooks were a new process to the participants, they did not regard them as an embedded part of their organisation's processes and thus did not spend a great deal of time on considering risks beyond the scope of the workshop. Where an organisation was to fully adopt and embed the process, further priority could be given to this part of the process. This will be an interesting area to monitor going forward in the project.

\subsection{Next Steps}

As previously mentioned, 3 workshops have been carried out with key stakeholders in the NINES project. However, it is intended to carry out a second tranche of workshops with the same stakeholders 12 months later. This is because it is recognised that the project environment constantly changes, the project itself will have moved on, and the knowledge of the participants will have changed as a consequence. It is therefore anticipated that the output from the second tranche of workshops will be significantly different (in content and structure) from the first tranche highlighting the need for regular assessment of risks on the project. These workshops will therefore consider how risk priorities have changed over time - taking account of the dynamic nature of risks and their interrelationships. 
The risk insights generated through the workshops also inform analysis to support the decision about the design of the new power station particularly its capacity. This decision model formalism requires the holistic risks identified to be classed and defined as a decision, uncertainty or consequence variable from the perspective of SHEPD as the decision-maker. We are exploring how to translate the risk maps created by multiple-stakeholders into a formal decision model as well as extending our analysis to elicit subjective probability judgements (Bedford et al, 2006; Quigley et al, 2008; Williams et al, 1997) from key stakeholders to populate the decision model. Thus the workshops and workshop processes have provided a powerful starting point in terms of thinking about the risks of the project, and a good basis upon which to ensure that the changing nature of a wide range of risks are considered throughout the life of the project.

Finally consideration regarding the types of projects amenable to risk workshops and whether adaptations are required would add depth to the process. The project addressed in this paper is multi-million dollar, extremely complex, and involved a range of stakeholder groups. However, consideration could be given to determining how the process can be extended to support projects that encompass a very large stakeholder base. Likewise determining the appropriate number and duration of workshops necessary to get both a detailed understanding as well as comprehensive capture of risks could further add to the robustness of the approach.

\section{Acknowledgements}

The authors would like to acknowledge the support they received from SHEPD and those attending the risk management workshops.

\section{References}

Ackermann, F. (2012). Problem Structuring Methods 'in the dock': Arguing the case for Soft OR' European Journal of Operational Research Society; 219 (3) 652-658

Ackermann, F. \& Eden, C. (2005). Using Casual Mapping with Group Support Systems to Elicit an Understanding of Failure in Complex Projects: Some Implications for Organizational Research. Group Decision and Negotiation, 14: 355-376.

Ackermann, F. and Eden, C. (2010). The Role of Group Decision Support Systems: Negotiating Safe Energy, in

Eden, C. and Kilgour, D. M., (Eds). The Handbook of Group Decision and Negotiation. 285-299, Dordrecht: Springer.

Ackermann, F. and Eden, C. (2011a). Strategic Management of Stakeholders: theory and practice, Long Range 
Ackermann, F. and Eden, C. (2011b).Making Strategy: Mapping Out Strategic Success, Sage, London

Ackermann, F., Eden, C., Williams, T. \& Howick, S. (2007). Systematic risk assessment: a case study. Journal of Operational Research Society; 58: 39-51.

Ackoff, R (1981). The art and science of mess management: Interfaces; 11: 20-26

Bedford, T., Quigley, J., Walls, L. (2006). Expert elicitation for reliable system design. Statistical Science; 21:4 $428-450$

Bryson, J.M., Ackermann, F., Eden, C. and Finn, C. (2004).Visible Thinking: Unlocking Causal Mapping for Practical Business Results, Wiley, London

Cooper, K.G. (1994). The $\$ 2000$ hour: How managers influence project performance through the rework cycle.

Project management journal, 16: 131-138

Duarte, D.L., Snyder, N.T. (1999). Mastering Virtual Teams: Strategies, tools, and techniques that succeed. Jossey-Bass, San Francisco.

Eden, C. and Ackermann, F. ‘(1998).Analyzing and Comparing Idiographic Causal Maps’ in C. Eden, and J.C. Spenders (Eds) Managerial and Organizational Cognition: Theory, Methods and Research, 192-209, Sage, London.

Eden, C., Ackermann, F. \& Williams, T. (2005).The Amoebic Growth of Project Costs. Project Management Journal, 36: 15-27.

Eden, C., Williams, T., Ackermann, F. and Howick, S. (2000). “On the nature of disruption and delay”, Journal of Operational Research. 51: 291-300

Eden, C and Ackermann, F. (2010). Negotiating Agreements: The Role of Causal Mapping and a Group Decision Support Systems, in P.C. Nutt and D..Wilson (Eds). The Blackwell Handbook of Decision Making, 231-272 Wiley-Blackwell London

Engwall, M. (2003). No project is an island: linking projects to history and context. Research Policy, 32, 789808.

Fang, C., Marle, F., Zio, E., et al. (2012). Network theory-based analysis of risk interactions in large engineering projects. Reliability Engineering \& System Safety; 106: 1-10

Flyvbjerg, B., Bruzelius, N. \& Rothengatter, W. (2003). Megaprojects and Risk: An Anatomy of Ambition, Cambridge, Cambridge University Press.

Hartman, F. (2003). Proactive risk management - myth or reality? In: Kahkonen, K. \& Arrto, A. K. (eds.) Managing Risks in Projects. London: E \& FN Spon. 
Harvey, J. 1988. The Abilene Paradox: the management of agreement. Organizational Dynamics, Summer: $17-$ 34

Howick, S., Ackermann, F., Andersen, D. (2006). Linking event thinking with structural thinking: methods to improve client value in projects. System Dynamics Review. 22: 113-140

Janis, I. L. 1972. Victims of Group Think. Boston, MA.: Houghton Mifflin Jessup, L. and Tansik, D.A. (1991).

Decision Making in an Automated Environment: The effects of Anonymity and Proximity with a Group Decision Support System, Decision Science, 22, 266-279

Jessup, L. and Valacich, J. (1993).Group Support Systems: New Perspectives. New York: Macmillan Kazemi, R., Mosleh, A. (2012). Improving Default Risk Prediction Using Bayesian Model Uncertainty Techniques. Risk Analysis 32:11 1888-1900

Maznevski, M. L., \& Chudoba, K. M. (2000). Bridging space over time: Global virtual team dynamics and effectiveness. Organization Science, 11(5), 473-492.

Morris, P., W., G. \& Pinto, J. K. (2004).The Wiley Guide to Managing Projects, New Jersey, John Wiley \& Sons.

Pauleen, D., \& Yoong, P. (2001). Facilitating virtual team relationships via Internet and conventional communication channels. Internet Research, 11(3), 190-202.

Project Management Institute. (2011).A Guide to the Project Management Body of Knowledge, $4^{\text {th }}$ Edition, Project Management Institute, Pennsylvania

Quigley, J., Bedford, T. and Walls, L. (2008). 'Eliciting a Prior Distribution', Encyclopaedia of Statistics in Quality and Reliability, Wiley (ed: Ruggeri, Kennett and Faltin)

Rittel, H., and Weber, M. (1973). Dilemmas in a general theory of planning. Policy Sciences 4 155-169

Rosenhead, J, and Mingers, J. (2001). Rational Analysis in a Problematic World. Wiley, London

Scotland, A.L., Ackermann F and Howick S (2011). Facilitation of Problem Structuring Methods with Virtual

Teams. Paper presented at the OR53 Annual Conference, Nottingham, UK, 6-8 September

Sterman J. (2000). Business Dynamics: Systems Thinking and Modeling for a Complex World. Irwin/McGrawHill. Chicago.

Valacich, J., Jessup, L., Dennis, A. and Nunamaker, J. A conceptual framework of Anonymity in Group Support Systems, Group Decision and Negotiation, (1992) 1, 219-242

Williams, T. (1995). A classified bibliography of recent research relating to project risk management. European Journal of Operational Research, 85, 18-38. 
Williams, T. (2000). Systematic Project Risk Management: The Way Ahead. International Journal of Risk Assessment and Management 1: 149-159

William, T. (2002). Modelling Complex Projects, Wiley. Chichester.

Williams, T.M., Ackermann, F.R. and Eden, C.L. (1997). Project risk: systemicity, cause mapping and a scenario approach, in, K.Kahkonen and K.A.Artto (Eds) Managing Risks in Projects. E\&FN Spon, London. ISBN 041922990 pp 343-352.

Williams, T.M., Eden. C., Ackermann, F. and Tait, A (1995). 'Vicious circles of parallelism' International Journal of Project Management, 13 (3): 151-155

Williams, T., Ackermann, F., Eden, C. and Howick, S. (2004) ‘Learning from Project Failure’ Managing Knowledge in Project Environments' in P.Love, Z.Irani, and P.Fong (Eds) Knowledge Management in Project Environments. Elsevier / Butterworth-Heinemann

Figure 1: Example of a group using the Group Support System to surface and review risks

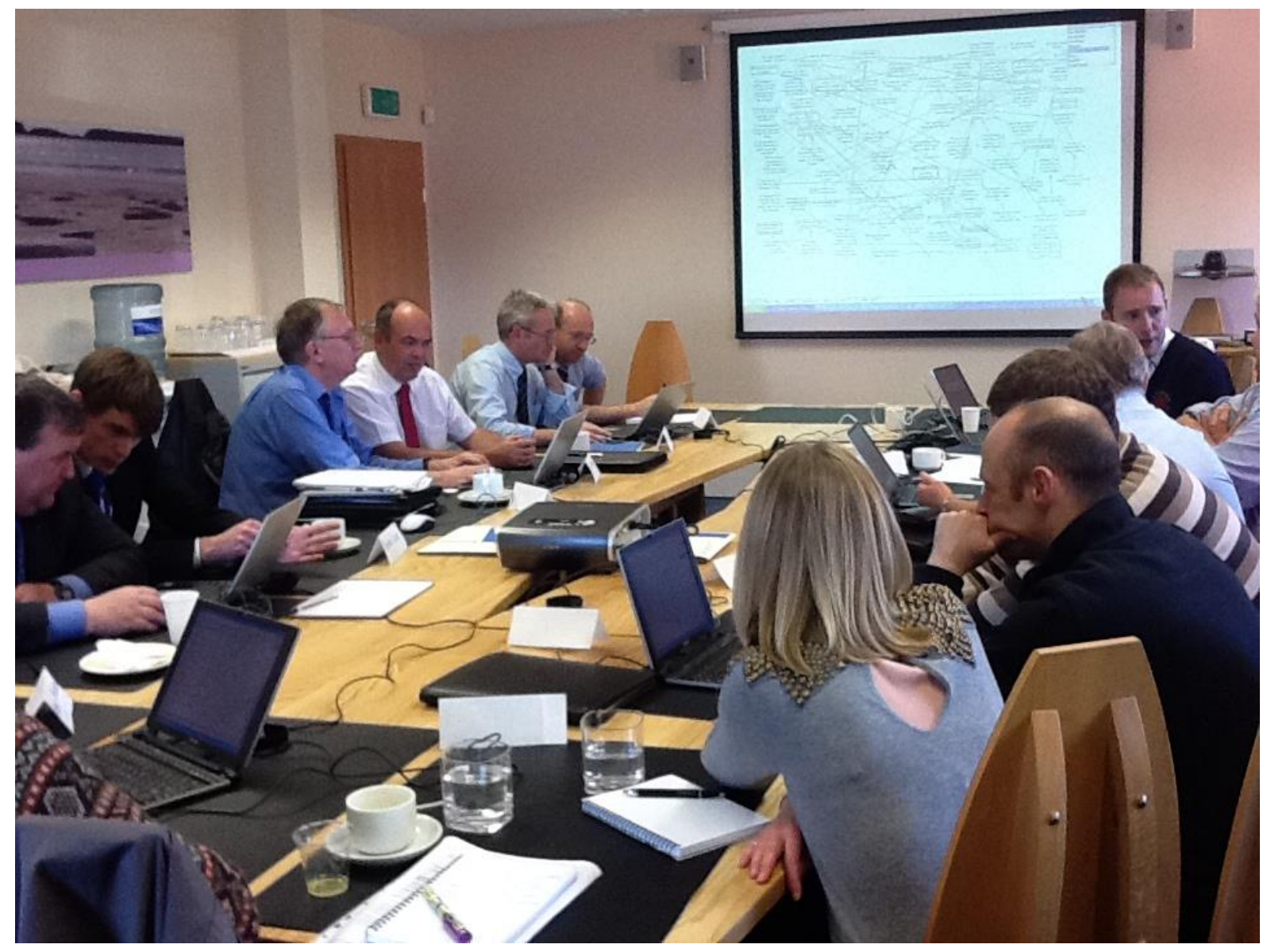


Figure 2: a small segment of a map

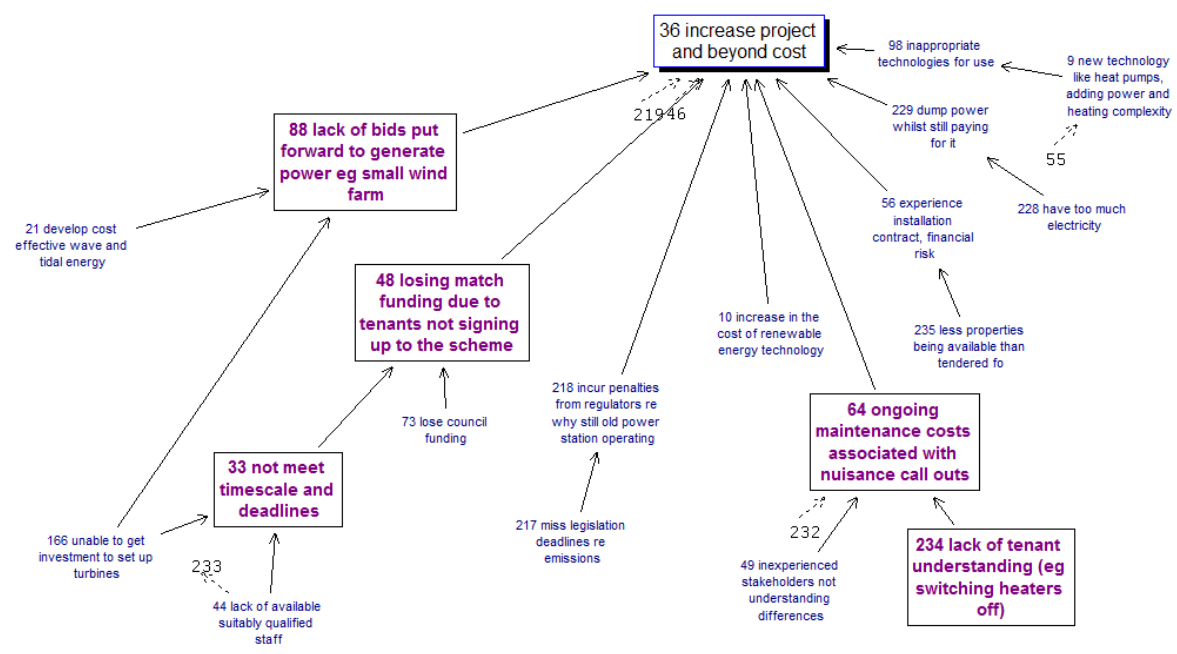

Note: The numbers preceding each risk event are reference tags used to facilitate manipulation of the data.

Legend: the statements boxed and shadowed are outcomes, statements in bold with boxes are key issues, the remaining statements are additional information. Numbers attached with dotted arrows represent additional material.

Figure 3: Extract from the SHEPD risk map that includes feedback loops.

Each of the arrows should be read as 'may lead to', except for those arrows with a negative sign at the arrow head which should be read as 'may lead to NOT'. 


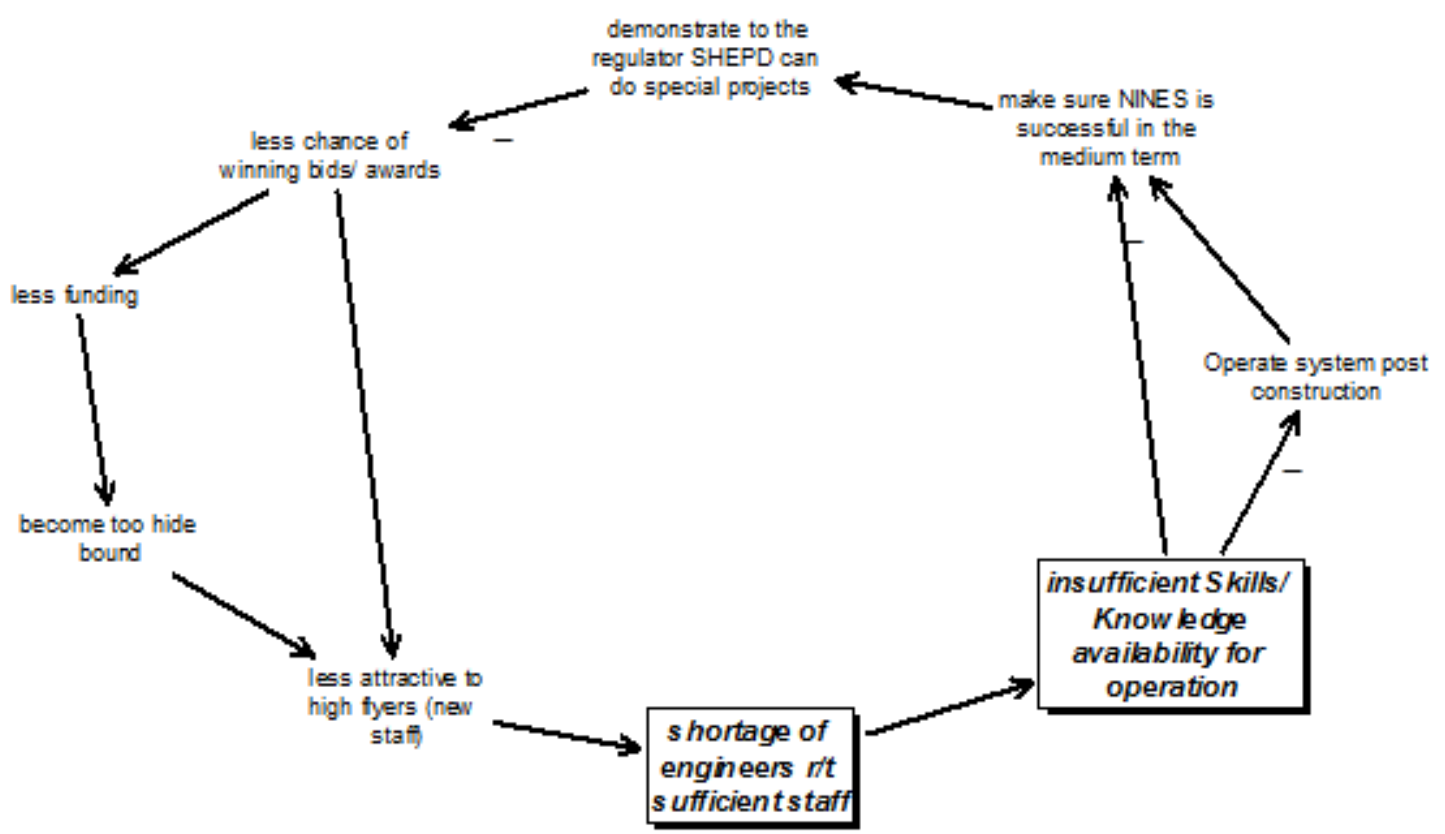


Appendix 1- Summary of Process

\begin{tabular}{|c|c|c|c|c|c|}
\hline Stage & Process & Output & $\begin{array}{l}\text { Benefits of } \\
\text { process }\end{array}$ & $\begin{array}{l}\text { Limitations of } \\
\text { process }\end{array}$ & $\begin{array}{l}\text { Additional } \\
\text { Contribution to } \\
\text { standard PRR } \\
\text { process }\end{array}$ \\
\hline 0 & $\begin{array}{l}\text { Selection of } \\
\text { Participants }\end{array}$ & $\begin{array}{l}\text { Ensure breadth and } \\
\text { depth of knowledge } \\
\text { and involve those } \\
\text { with interest and } \\
\text { power on the project }\end{array}$ & $\begin{array}{l}\text { Shared } \\
\text { understanding } \\
\text { Anonymity } \\
\text { Inclusive }\end{array}$ & $\begin{array}{l}\text { Availability can } \\
\text { restrict } \\
\text { participation }\end{array}$ & $\begin{array}{l}\text { Stakeholder } \\
\text { analysis is now } \\
\text { being given more } \\
\text { emphasis in } \\
\text { PMBOK }\end{array}$ \\
\hline 1 & $\begin{array}{l}\text { Elicitation } \\
\text { and clustering } \\
\text { of Risks }\end{array}$ & $\begin{array}{l}\text { Enables consideration } \\
\text { of a wide and } \\
\text { comprehensive range } \\
\text { of risks }\end{array}$ & $\begin{array}{l}\text { Fast and thus } \\
\text { productive } \\
\text { elicitation } \\
\text { Interactive } \\
\text { process }\end{array}$ & $\begin{array}{l}\text { Gaining correct } \\
\text { balance of time } \\
\text { spent between } \\
\text { elicitation and } \\
\text { linking of risks } \\
\text { for the specific } \\
\text { group }\end{array}$ & $\begin{array}{l}\text { Comprehensive } \\
\text { consideration of } \\
\text { risks beyond } \\
\text { technical and } \\
\text { financial }\end{array}$ \\
\hline 2 & $\begin{array}{l}\text { Structuring } \\
\text { and linking of } \\
\text { Risks }\end{array}$ & $\begin{array}{l}\text { Risk map that } \\
\text { captures how risks } \\
\text { impact one another }\end{array}$ & $\begin{array}{l}\text { Convergent and } \\
\text { augmented set of } \\
\text { views } \\
\text { Interactive } \\
\text { process } \\
\text { Holistic view of } \\
\text { risks }\end{array}$ & $\begin{array}{l}\text { Gaining correct } \\
\text { balance of time } \\
\text { spent between } \\
\text { elicitation and } \\
\text { linking of risks } \\
\text { for the specific } \\
\text { group }\end{array}$ & $\begin{array}{l}\text { Considers risk } \\
\text { systemicity }\end{array}$ \\
\hline 3 & $\begin{array}{l}\text { Prioritisation } \\
\text { of Risks }\end{array}$ & $\begin{array}{l}\text { Share views on } \\
\text { probability and } \\
\text { impact of risks } \\
\text { Prioritised agenda of } \\
\text { those risks that need } \\
\text { most attention }\end{array}$ & $\begin{array}{l}\text { Prioritised agenda } \\
\text { is supported } \\
\text { through detailed } \\
\text { maps } \\
\text { Interactive } \\
\text { process }\end{array}$ & $\begin{array}{l}\text { Whilst anchor } \\
\text { points are } \\
\text { requested, } \\
\text { variation is likely } \\
\text { between } \\
\text { participants }\end{array}$ & $\begin{array}{l}\text { Consideration of } \\
\text { probability and } \\
\text { impact undertaken } \\
\text { holistically, with } \\
\text { reference to risk } \\
\text { dependency } \\
\end{array}$ \\
\hline 4 & Workbooks & $\begin{array}{l}\text { Provides time to add } \\
\text { to or amend the risk } \\
\text { maps }\end{array}$ & $\begin{array}{l}\text { Promotes the risk } \\
\text { map as a dynamic } \\
\text { rather than static } \\
\text { tool }\end{array}$ & $\begin{array}{l}\text { Can be difficult to } \\
\text { engage with if did } \\
\text { not participate in } \\
\text { workshops } \\
\text { Getting people to } \\
\text { take time out of } \\
\text { their day job to } \\
\text { consider these }\end{array}$ & $\begin{array}{l}\text { Continuous } \\
\text { engagement of wide } \\
\text { variety of } \\
\text { stakeholders }\end{array}$ \\
\hline 5 & $\begin{array}{l}\text { Interviews } \\
\text { with } \\
\text { participants }\end{array}$ & $\begin{array}{l}\text { Allow participants to } \\
\text { add to or amend the } \\
\text { maps } \\
\text { Gain feedback on } \\
\text { process }\end{array}$ & $\begin{array}{l}\text { Participants are } \\
\text { able to reflect } \\
\text { further on risks } \\
\text { facing the project } \\
\text { and add links and } \\
\text { risks }\end{array}$ & & $\begin{array}{l}\text { Continuous } \\
\text { engagement of a } \\
\text { wide variety of } \\
\text { stakeholders }\end{array}$ \\
\hline 6 & $\begin{array}{l}\text { Analysis of } \\
\text { resultant } \\
\text { material }\end{array}$ & $\begin{array}{l}\text { Compare and contrast } \\
\text { risk maps, Explore } \\
\text { systemicity of risk, } \\
\text { identify most } \\
\text { significant risks and } \\
\text { consider impact of } \\
\text { feedback loops }\end{array}$ & & & $\begin{array}{l}\text { Analyse the impact } \\
\text { of the } \\
\text { interdependence of } \\
\text { risks }\end{array}$ \\
\hline 7 & $\begin{array}{l}\text { Report } \\
\text { findings }\end{array}$ & $\begin{array}{l}\text { Highlight emergent } \\
\text { themes, significant } \\
\text { and priority risks }\end{array}$ & & & \\
\hline
\end{tabular}

